Cuadernos del CILHA n 34 - 2021 | publicación continua

ISSN 1515-6125 | EISSN 1852-9615

https://revistas.uncu.edu.ar/ojs3/index.php/cilha

CC BY-NC 2.5 AR

Recibido: 13/05/2021 Aprobado: 10/06/2021

PP. 1-31

DOI: https://doi.org/10.48162/rev.34.009

\title{
Trans-Urbanismo: economía cuir afectiva en el trabajo sexual por mujeres trans en los años 80 en San José, Costa Rica
}

Trans-Urbanism: Affective care economy in the sex work by trans gender women in the 80's in San José, Costa Rica

Luis Alonso Rojas Herra

https://orcid.org/0000-0002-3503-4214

Universidad Nacional de Costa Rica

Irojash@uned.ac.cr

Costa Rica

Resumen: Este trabajo surge de un proceso de aprendizaje construido en conjunto con varias mujeres transgénero que trabajaron en comercio sexual en distintas ocasiones en la capital de San José Costa Rica durante la década de los 70 y la década de los 80 . Este texto representa un esfuerzo por cartografiar las experiencias de vida de estas mujeres en torno a las prácticas y dinámicas de expulsión y violencia a las que eran sometidas en esas décadas por ejercer trabajo sexual.

Muchas de las experiencias de vida visibles en el texto ponen en evidencia el potencial corporal de estas mujeres para poder resignificar sobre el espacio urbano donde se desarrolla el comercio sexual en esas décadas y construir vínculos afectivos de cooperativismo entre ellas. Mujeres que se posicionan desde posturas contestarías, en 
un contexto Estatal donde el régimen liberal y hetero-patriarcal es la norma hegemónica de homogenizar la ciudadanía. La intención de este texto es reflexionar sobre la producción y reproducción de espacios comunes o de acumulación afectiva que se han abordado de manera emergente durante el proceso investigativo del proyecto inscrito en el Centro de Investigación en Cultura y Desarrollo (CICDE), de la vicerrectoría de investigación de la Universidad Estatal a Distancia (UNED) en costa Rica bajo el nombre de: "Cuerpos y territorios indómitos: cartografía disidente Josefina".

Palabras Clave: Trans-territorialidad, Trans-regionalización, Trans-Urbanismo, Economía cuir.

\begin{abstract}
This paper emerge from a learning process built in conjunction with several transgender women who worked in the sex trade on different occasions in the capital of San José Costa Rica during the 70's and 80's. It is an effort to map the life experiences of these women around the practices and dynamics of expulsion and violence to which they were subjected in those decades for engaging in sex work. Many of these life experiences highlight the bodily potential of these women to be able to resignify and build affective bonds within which they have developed their work for decades. From positions you would answer, in a context where the liberal and hetero-patriarchal regime is the hegemonic norm. The intention of this text is to reflect on the production and reproduction of common spaces or of affective accumulation that have been analyzed in an emergent way during the investigative process of the project registered in the Center for Research in Culture and Development (CICDE), of the vice-rectory of Research from the State Distance University (UNED) in Costa Rica under the name of: "Bodies and untamed territories: Josefina dissident cartography".
\end{abstract}

Keywords: Trans-territoriality, Trans-regionalization, Trans-Urbanism, Queer economy.

\title{
Nota Introductoria
}

Este texto está escrito y pensado en clave playisima (Falconí, 2018) que etimológicamente hablando procede de la palabra playo, acuñado por la idiosincrasia costarricense durante la modernidad para referirse de manera despectiva a la persona homosexual y sodomita.

El termino playada, dentro de la jerga de las clases sociales más empobrecidas o populares, como le llaman las clases más privilegiadas, se utiliza para feminizar 
prácticamente cualquier cosa que el limitado pensamiento heteronormativo no comprenda o acepte como lo correctamente masculino o masculinizado. Por ejemplo, un abrazo afectivo entre dos personas que se ven masculinas es una playada. Precisamente este texto está escrito desde ese lugar, desde la playada (Falconí, 2018).

\section{Introducción}

Después de un año de tener el privilegio de colaborar ${ }^{1}$, en diversas ocasiones, con distintas mujeres transgénero que trabajaron en comercio sexual para el proyecto de investigación mencionado anteriormente, me di cuenta de aspectos significativos de contenido epistémico y metodológico en las técnicas y herramientas formales de investigación para abordar esta población en general que se reproducen desde el espacio académico. Aspectos que no deseaba reproducir en los textos y productos que pudiera publicar de dicho proceso.

El primero de ellos, es la aproximación que, desde la academia (un espacio privilegiado) el investigador (una persona privilegiada) hace con frecuencia a los cuerpos y saberes de estas mujeres. La mayoría de las veces esta es una aproximación desde una perspectiva patológica y victimaria sobre los cuerpos y afectos de estas mujeres. Perspectivas que reproducen discursos de lastima y reduccionismo de sus procesos de emancipación ciudadana. Que, además, no permiten la autonomía de su conocimiento y de sus propias formas de representación en estos espacios.

Y la segunda, es la expropiación del conocimiento que ha reproducido el espacio académico hacia estas mujeres sin retribuirles productos académicos que contribuyan al empoderamiento y autonomía real de sus procesos de emancipación ciudadana. Al contrario, el espacio académico solo reproduce un modelo de explotación del conocimiento y violencia de sus afectos, del cual todas las personas que vivimos dentro de un régimen capitalista somos víctimas, pero que las personas que pertenecen a grupos minorizados y vulnerabilizados experimentan manera sistemática, cotidiana y estructural por la condición de desigualdad en la que viven.

\footnotetext{
${ }^{1}$ Esta colaboración fue posible a la asociación mujeres trans: Transvida. Que se ubica en barrio San Cayetano en la provincia de San José, la capital de Costa Rica.
} 
Estas reflexiones personales y preliminares me llevaron a tomar la decisión de publicar los resultados de la investigación en dos textos académicos, que son complementarios. Un primer texto en clave ensayo académico, con el contenido epistémico y etimológico que contribuya a la propuesta de un marco de razonamiento propio en sentido decolonial con el fin de contribuir a la producción de un discurso contestario del régimen heteronormativo liberal imperante en los Estados soberanos occidentalizados de la región latinoamericana. Régimen que ha expulsado y anulado los saberes de estas mujeres por décadas. Este primer texto se concibe como un ejercicio de interpelación de los privilegios que un grupo de personas damos por sentado al tener acceso a un grupo de derechos ciudadanos inherentes que para estas poblaciones de mujeres trans en comercio sexual siguen sin poder ejercer.

Por otro lado, un segundo texto, el cual estás leyendo, donde se evidencia los hallazgos de la experiencia urbana de un grupo de mujeres transgénero que trabajaron en comercio sexual. Utilizando la técnica etnográfica empleada durante los recorridos urbanos realizados en la ciudad de San José durante el 2019 por los espacios donde estas mujeres ejercían trabajo en comercio sexual durante la década de los setentas y ochentas.

Para abordar este texto, es recomendable posicionarse desde la empatía y el respeto, la existencia de los cuerpos de estas mujeres es la evidencia de una lucha cotidiana por afirmar (Fournier, 2017, p. 7) y revindicar los derechos que les ha negado el Estado. Entender que la visibilidad en los espacios públicos de las personas trans se considerada un atentado contra para el régimen heteronormativo, La presencia de sus cuerpos en el espacio publico causa malestar en las personas fundamentalistas que viven el régimen de manera ortodoxa por una sencilla razón: Pone en evidencia que su forma de vivir la vida bajo un régimen heteronormalizado es una falsa ficción construida y que solo unos cuantos privilegiados, que acceden al régimen, gozan de sus beneficios.

Y, por último, quiero expresar mi profundo agradecimiento por los aportes significativos que distintas chicas trans me ofrecieron. Sin el conocimiento de estas otras mujeres sería imposible haber concebido este texto. Pero en especial quiero agradecerles por permitirme descubrir en el proceso una de los mayores aprendizajes que he tenido: la empatía. Al mismo tiempo, mi experiencia con estas mujeres me permito cuestionar los 
hábitos y metodologías de aprendizaje producidas y ejercidas de manera dominante desde un espacio privilegiado como la academia que en muchas ocasiones re-produce prácticas pedagógicas jerárquicas y patriarcales.

Este texto es un producto intelectual compartido con Natalia Porras, Fabiola conocida como: madre tierra y mística de la naturaleza con más de 10 años de activismo ecológico-urbano, Lorna, Andrea Munhurtsberger (quien fue miss cucharones 1996) y Alondra quien murió en el 2019 y no pudo ver este producto finalizado. Pero, sobre todo, esta cartografía es el resultado de trasladar al papel, el conocimiento que amablemente Kassandra me compartió con el fin de contribuir a un archivo de memoria trans. Kassandra ejerció el comercio sexual desde finales de la década de los 70's hasta mediados de los años 80’s en la ciudad de San José, Costa Rica.

Quiero aclarar que a ninguna de estas mujeres le pude retribuir de manera económica como realmente lo merecían por permitir utilizar su conocimiento. Así que espero hacerles honor y que este texto contribuya a sus procesos de emancipación y empoderamiento ciudadano que ellas en conjunto con otras colectivas de mujeres trans, guerreras y hermanas lideran en la actualidad en San José, Costa Rica.

Este texto está dedicado a todas las mujeres trans asesinadas de manera violenta, sin visibilidad por los medios de comunicación hegemónica del país, que fueron recordadas durante el proceso en las distintas entrevistas realizadas. En memoria de:

1. Catalina: asesinada en el antiguo Hotel Bristol ubicado en barrio la California en San José, Costa Rica.

2. Petunia: quien fue asesinada por su propio cliente al darse cuenta que le robó el reloj de mano. Petunia recibió un disparo en la cabeza al frente de todas sus amigas en la esquina diagonal a donde vivía (Avenida 7, calle 16, San José, Costa Rica).

3. La Trieta quien murió en el juego mecánico el martillo en las fiestas cívicas en el distrito de Zapote en San José, frente a todo el público presente sin que nadie hiciera algo por ayudarla. 
4. A Mónica, quien un desconocido en carro la empujó de un puente peatonal de la ciudadela 15 de setiembre en Hatillo por llevar una muñeca de trapo en las manos.

5. A Michael quien murió asesinada en cuarto de motel de San Francisco, bajo el impacto de 25 balas en el cuerpo cuando el cliente se dio cuenta que tenía pene.

6. A Bon Esponja quien la quemaron viva en Pavas y sus restos las cubrieron con basura en un lote abandonado en el mismo lugar.

\section{Trans-territorialidad}

Este artículo puede ser considerado la continuación de distintos esfuerzos teóricos para contribuir a construir un discurso militante (Vengas y Moreno, 2020, p. 83) en clave homosexual (Falconí, Castellanos y Viteri, 2014) que aporte a un devenir tras-territorial. Muchos de las nociones conceptuales citadas y de las etimologías utilizadas en esta propuesta, son parte de un esfuerzo por proponer una torti-trans-epistemología playisima propia y situada de la disidencia por identidad y orientación sexual no hegemónica de la región latinoamericana específicamente en Costa Rica.

Este escrito es un esfuerzo reflexivo para mostrar la capacidad y la fuerza que esas nociones conceptuales y etimológicas, desde la disidencia por identidad y orientación sexual no hegemónica pueden producir para transformar discursos dominantes que se reproducen en los espacios privilegiados, heterosexualizados, colonizados y blanqueados (Falconí, 2018), como el que prevalece y se reproduce en la academia de manera hegemónica por la vía jerárquica y masculinizada (Cervetto y López, 2017).

Para aproximarnos a las prácticas anti-ciudadanas de un devenir tras-territorial, primero hay que comprender y des-construir desde una lectura interseccional y reivindicativa en clave trans-feminista playisima de cómo la hegemonía ha construido y formalizado la noción de territorio, bajo una lógica de expulsión que no visibiliza e incluye la contribución de los saberes de la disidencia militante por identidad y orientación sexual no hegemónica. Y que no reconoce el aporte, en términos de valor y uso del espacio, que estos grupos producen a la configuración de estos espacios o territorios (Rojas, 2018, p.59). 
¿Cómo? de-construyendo interpretaciones y concepciones que sostienen y privilegian mitos y regímenes fundadores hegemónicos sobre el territorio, la ciudadanía, el Estado y muchas otras fuentes epistémicas heterosexualizadas construidas desde el privilegio occidentalizado y blanqueado. Está propuesta intertextual invita a reflexionar sobre dos maneras de entender los procesos con el que los Estados soberanos hetero-capitalistas occidentalizados han perpetuado su poder:

El primero se debe a que los Estados soberanos hetero-capitalistas occidentalizados han construido un modelo sistemático y estructural hegemónico de organizar las sociedades modernizadas de occidente jerárquico y dicotómico (Rojas, 2020, p.124). Este modelo de organización territorial y ciudadano es muy complejo en la manera de actualizar sus regímenes fundadores (patriarcado y capitalismo), por lo tanto, también es innovador es sus formas de renovar sus mecanismos, tecnologías y métodos de control sobre los ciudadanos y el territorio en términos de soberanía. (Rojas, 2020, p. 125)

Y, el segundo, es que los Estados soberanos hetero-capitalistas occidentalizados se han favorecido históricamente de la condición de desigualdad estructural en que se fundaron los Estados soberanos precarizados oprimidos de tercer mundo desde el periodo del imperialismo en su origen hasta la actualidad. Este modelo organizacional aliado al capitalismo actualiza las formas de producción, consumo y acumulación de capital de las economías hegemónicas, a lo largo de más de 400 años (Sassen, 2010) perpetuando la hegemonía política de los países desarrollados sobre los de en vía de desarrollo.

Por eso desconfiar del aparato jurídico internacional que gestiona los Estados Soberanos occidentalizados a escala global y del aparato jurídico nacional que gestiona la soberanía a escala local, es clave para la disidencia (Rojas, 2020, p.132). Estos mitos postmodernos se construyen en concesos desde los sectores más privilegiados, donde la otredad y la disidencia no tienen representatividad. Por lo tanto, estos grupos quedan sin posibilidad de tener una incidencia activa en esos concesos de orden nacional y global. El empoderamiento ciudadano de estos colectivos desde la autonomía y la representatividad es primordial para un devenir tras-territorial. 
Tanto los instrumentos jurídicos internacionales como las políticas públicas nacionales de los países de la región latinoamericana son de carácter asistencialistas y colonizadores que no pretenden dar respuesta a la desigualdad estructural de los Estados soberanos precarizados oprimidos occidentalizados de tercer mundo arrastran desde la colonización. Para accionar con precisión la disidencia debe asimilar que ningún país que se autodenomina de manera favorable como desarrollado quiere someter sus regímenes fundadores (patriarcado y el capitalismo) productores de privilegios a una transformación profunda que los haga perder hegemonía, aunque esto signifique un posible devenir de la igualdad y la paz entre los países globalizados de occidente de que tanto se jactan los representantes de los gobiernos de esos mismos países (Rojas, 2020, p. 79).

En Latinoamérica no podemos seguir perpetuando la reproducción de consensos de pensamiento eurocentrista, donde un país que se construye bajo un régimen soberano se ve debilitado y expropiado constantemente por interés de orden y poder global. Poniendo constantemente en crisis su soberanía. La región centroamericana es un cúmulo de procesos y regímenes de bio-poder (Preciado, 2020), políticos y sociales occidentalizados con capacidad de renovarse y que son gestionados desde la hegemonía desde los intereses particulares de los países en desarrollo para mantener su estatus de poder.

Para una propuesta epistémica de carácter tras-formador del cuerpo y la trasconfiguración territorial como está, es vital entender a capacidad que tienen los Estados soberanos hetero-capitalistas occidentalizados para gestionar y administrar las distintas formas de producir redes globales desterritorializadas de economías hegemónicas (Sassen, 1999) simbiontes que configuran el territorio a benéfico de los grupos privilegiados de mayor poder político y capital por medio de una diversidad de prácticas de subordinación.

La producción de redes globales de la economía hegemónica, se rige por principios fundadores de un régimen neoliberal capitalista, que sostiene y se beneficia de una diversidad de sub-redes de economías no hegemónicas (Sassen, 2003) como la producida por trabajo informal. El $60 \%$ de la población mundial, la mayoría con rostro de mujer, trabaja en condiciones de informalidad y desigualdad (Benach, 2008, p. 39). 
Del $100 \%$ de trabajadores informales el $20 \%$ lo hacen en condición de precariedad y esclavitud (Benach, 2008, p.39). El otro $80 \%$ restante que trabaja en condiciones de informalidad y desigualdad (Benach, 2008, p. 39).

Estos datos estadísticos se utilizan por las fuentes internacionales de financiamiento hegemónico para categorizar los Estados soberanos latinoamericanos. Y bajo estas categorías distribuir los recursos financieros y aumentar sus utilidades por medio del incremento de la deuda internacional de nuestros países al Fondo mundial Internacional (FMI) y llamar a esa condición de endeudamiento "en vías de desarrollo". Estas instancias presentan informes para cuantificar sus obras benéficas en la región y de esta manera solapa calmar su conciencia colonizadora.

Para efectos de este texto, se va centrar en el efecto que tiene la red global de la economía formal producida del turismo internacional que se sostiene de procesos informales de explotación y expropiación territoriales a escala local que inciden en la soberanía de un país. Para contextualizar, solo en Costa Rica el turismo (antes del covid19) representa el $22,4 \%$ del PIB, superior a los ingresos que genera las agroindustrias del café y el banano, las cuales fueron el primer sector económico del país por mucho tiempo, antes del debilitamiento estructural que afectó este sector y que se dio al solicitar el primer préstamo de dinero al fondo mundial en la década de los años ochenta. La labor que se necesita para llevar a cabo la acumulación de capital exitosa de la industria del turismo internacional se basa en la condición de desigualdad estructural en la que se gestiona. Ya que toma por hecho la división de clases sociales, donde los pobres atienden a los ricos (Rivers-Moore, 2017, p. 61).

La mayoría de las economías no hegemónicas siguen los principios de una lógica del modelo neoliberal capitalista. Esto quiere decir que también son economías oprimidas donde se reproduce la privatización del bien común de las fuentes de producción y se explota a la mano de obra informal. Donde el $80 \%$ de personas laboran en condiciones de desigualdad y el otro $20 \%$ en condición precarizada o de esclavitud para ofrecer un servicio donde solo lucra un monopolio.

Vamos a ejemplificar estos conceptos abstractos con el fin de aproximarnos a la función de estos mecanismos a escala regional. El turismo Internacional es una economía hegemónica formal para los Estados soberanos hetero-capitalistas occidentalizados 
que se benefician de su producción a gran escala por que les permite acumular capital. El turismo Internacional es parte de una red de economías hegemónicas globales y desterritorializadas que inciden en la configuración de los territorios que atraviesa. En Latinoamérica esta economía favorece la implementación de políticas nacionales de corte neoliberal que permite el monopolio de diversos bienes y servicios públicos, como el bien común, por distintos medios jurídicos.

Por ejemplo, las concesiones a lo largo de todos los golfos de la región pacífico y atlántico del país Costa Rica. Estas concesiones se dan en condiciones de desigualdad, en términos jurídicos, donde se le otorga el derecho a inversionistas y desarrolladores privados, representados por grandes cadenas hoteleras, para administrar porciones del territorio nacional. El resultado es la privatización y la explotación de bienes y servicios públicos como el recurso hídrico o de los espacios públicos marítimos (playas) por parte de grandes cadenas hoteleras. Un ejemplo de una concesión mal consensuada es la del golfo de papagayo, la cual cuenta con grandes vacíos jurídicos en su redacción que le permite a la parte desarrolladora privada acceder a una serie de privilegios que solo benefician al inversionista privado, como lo son los privilegios fiscales, entre ellos les permite a los dueños de casas de lujo de la élite extranjera pagar bajos impuesto municipales por esa vivienda. O que empresas hoteleras internacionales pagan los mismos impuestos por el uso del agua, que utilizan para mantener la estética de sus canchas de golf y gigantescas piscinas en zonas de clima seco, que las comunidades rurales empobrecidas vecinas para uso residencial (Gaceta, 1993).

Al mismo tiempo estos grandes inversionistas y desarrolladores privados también se benefician de la explotación y precarización de un sector considerado mano de obra barata, que permite la acumulación de capital a los grandes inversionistas. El turismo Internacional se sostiene de una red de economías no hegemónicas que funcionan de manera indirecta (no legitimado por los Estados soberanos hetero-capitalistas occidentalizados).

Una de estas redes es el tráfico y explotación de personas con fines de comercio sexual internacional. Solo en el mundo existen más de 5 millones de personas que viven en esta condición. Este grupo representan el $20 \%$ de las personas que trabajan en 
condición informal precaria (Benach, 2008, p. 39) produciendo bienes y servicios paupérrimos.

Al hacer una lectura homosexual de los datos estadísticos oficiales Internacionales aplicados en nuestro país, nos arroja que en Costa Rica hay 360 personas LGBTI ${ }^{2+}$. Transitando por este circuito en este momento mientras usted lee este texto. Donde más de la mitad unas 180 personas son mujeres lesbianas, bisexuales o trans. El 98\% de estas mujeres son víctimas de explotación sexual que sostienen enclaves o distritos económicos especializados (Sassen, 2015, p.23).

Costa Rica es administrado por gobiernos que se favorecen y reproducen del modelo de Estado soberano heteronormativo y neo-liberal occidentalizado solo que se encuentra en condición de desigualdad, pero que no reconoce que pertenece a ese circuito global de comercio sexual. Por lo que condena la práctica del turismo sexual, pero al mismo tiempo la facilita y se beneficia de ella indirectamente (Rivers-moore, 2019). El turismo sexual internacional incide en los procesos de transformación del territorio nacional de maneras muy particulares o tropicalizadas.

El turismo Internacional, al igual que todas las economías hegemónicas, producen circuitos que funcionan como una subred que permite la movilidad de esos bienes y servicios para que transiten por la espacialidad territorial global al mismo tiempo que definen los distritos especializados según la demanda. Cada uno de estos distritos cuenta con una robusta infraestructura que hace posible el funcionamiento adecuado del comercio sexual (Sassen, 2015, p. 95).

Para efectos de este texto solo vamos abordar nociones conceptuales muy escuetas de dos de las infraestructuras propuestas, que nos permitan aproximarnos a entender cómo opera la lógica espacial arquitectónica en estos contextos. Las redes se constituyen de un conjunto de distritos especializados de servicios sexuales sumamente

\footnotetext{
${ }^{2}$ Se utilizará el acrónimo $\mathrm{LGBTI}^{+}$en todo este texto para referirse a las categorías rígidas asignadas por el régimen heteronormativo impuestas a las personas disidentes de la sexualidad hegemónica.
} 
diversos, se encuentran geopolíticamente localizados y se conectan entre sí por dos tipos de infraestructura: la digital y la de movilidad.

La primera de estas se constituye por toda una comunidad global y local que utilizan una infraestructura tecnológica ya existente que les permite comunicarse, intercambiar, negociar, transportar, mercantilizar y hasta evaluar o hacer "reviews", sobre los bienes y servicios con fines sexuales que la red especializada ofrece. La infraestructura digital gestiona y permite la difusión de representaciones hegemónicas, romantizadas e idealizadas sobre los cuerpos colonizadores que consumen los servicios del turismo sexual y los bienes o cuerpos colonizados que producen ese servicio (Riversmoore, 2017).

Los circuitos trazan y configuran rutas de transferencia de un distrito a otro a escala global y local. Gestionando el desplazamiento masivo de bienes y recursos necesarios, en su mayoría los cuerpos colonizados que producen ese servicio, para llevar a cabo sus funciones. Lo que constituye el segundo tipo de infraestructura, la de movilidad. Dentro de estos recursos y bienes están los miles de cuerpos que representan a las personas migrantes de diversos países, que ejercen en el comercio sexual como única forma de sobrevivencia que la estructura del Estado Soberano heteronormativo occidentalizado le permite para poder acumular capital para acceder a ciertos "bienes" que una sociedad hetero-capitlista les ofrece.

Muchas de estas personas migrantes que se desplazan son víctimas de abuso sexual durante sus trayectos, en su mayoría mujeres (UNODC 2011), personas trans y homosexuales (scorts). La infraestructura de movilidad opera bajo una dialéctica de economía neoliberal que reproduce una lógica de expropiación del cuerpo endeudado (Preciado, 2014). Donde ingresar y mantenerse en la red lo posibilita el endeudamiento por lo que se encuentran en condición de desigual constantemente. Hay miles de personas que logran pagar altos precios por ser insertadas en estas redes de trata de personas. Las mujeres trans latinoamericanas que se endeudan para conseguir hasta quince mil euros (Gallo, 2019), suma de dinero que necesitan para ser importadas a Europa, para poder ofrecer servicios sexuales administrados y gestionados por un monopolio proxeneta. 
En las infraestructuras de movilidad existen insertados una variedad de tipologías arquitectónicas con distintos usos y valores. La supra estructura arquitectónica son todos los distintos espacios arquitectónicos que ofrecen las amenidades y cualidades espaciales favorables para que las prácticas de intercambio, negociación, transporte y todas las demás que existen en el comercio sexual se den de manera clandestina y segura ante la ley que las criminaliza.

Un conjunto de tipologías arquitectónicas configura un distrito. La especialidad del distrito lo define la demanda del consumidor. A pesar que su práctica se condena y se considera clandestina, las tipologías arquitectónicas se ordenan en el ámbito público y en el ámbito privado generando enclaves especializados. Muchas de las dinámicas de socialización e intercambio que genera el comercio sexual se llevan a cabo en las tipologías arquitectónicas ubicadas en el espacio público.

Otra característica inherente de las tipologías arquitectónicas es la temporalidad, son espacios mutables. Él usos y el valor político que estos espacios arquitectónicos tienen para las mujeres transgénero que trabajan en comercio sexual se modifican, cambian o re-significan con el paso del tiempo.

\section{Trans-regionalización}

Un espacio trans-territorial se configura bajo condiciones de desigualdad muy profundas y que tiene origen desde tiempos del imperialismo español hasta la configuración actual de los Estados soberanos hetero-capitalistas occidentalizados. Estos modelos de Estados modernizados reproducen discursos fuertemente misóginos y discriminatorios para legitimar y construir instrumentos jurídicos (leyes y normas), que favorecen prácticas de violencia con el fin de homogeneizar, castigar, sancionar y disciplinar a los grupos construidos como subalternos o la otredad por la ciudadanía hegemónica.

Construyendo diversas concepciones de grupos sociales denominados como "atrasados" o "peligrosos" hasta la actualidad, Estos grupos sociales atientan contra los procesos de modernización y saneamiento social que impulsan las ciudades latinoamericanas que imitan, en condición de desigualdad estructural, un modelo de 
Estado soberano occidentalizado y blanqueado para el paradigma de la modernidad (Quesada, 2011).

Cuando San José fue nombrada capital de Costa Rica la ciudad se vio transformada por procesos de saneamiento social producidos por el discurso de la modernización en Europa occidental. Este proceso implicó el impulso de un conjunto de políticas de corte liberal en tres ejes de acción o renovación urbana (Quesada, 2011). Estas políticas fueron ejecutadas bajo interés privados de sectores privilegiados y sin planificación lo que terminó en una serie de proyectos urbanos mal gestionados e inconclusos.

Este proceso iba de la mano de una serie de mecanismos de control jurídico y regulación social que aplicaron a la población con el fin de modernizar los hábitos de socialización públicos y privados de la ciudadanía hegemónica (Quesada, 2011). Pero también marcó las pautas para identificar cuales personas y lugares dentro de la ciudad se consideraban ilegítimos y cuales no calzaban dentro de estos consensos del paradigma moderno.

Durante el proceso de planificación inicial de la capital de San José, y bajo el paradigma de modernidad, se consideraron dos puntos como la periferia basados en parámetros del discurso de higiene predominante en la época, que tenía entre muchos objetivos, ensanchar las calles de la ciudad para que la ventilación natural desplazara fuera del centro de la ciudad los virus y bacterias producidas por los desechos de las personas que habitaban la ciudad (Quesada, 2011).

Durante esta época los centros hospitalarios se consideraban espacios que albergaban virus y bacterias por lo que se decidió ubicar dichos centros de salud en lo que se proyectaba iba ser el borde de la ciudad en aquel momento. El Hospital Calderón Guardia en la periferia norte de la ciudad y el hospital San Juan de Dios en la periferia oeste, ambos como puntos construidos de referencia de los límites de la ciudad.

Al lado del hospital San juan de Dios, al oeste de la ciudad y fuera del borde, se configuró unos de los primeros asentamientos informales registrados en la historia actual, constituido por un grupo de personas anti-ciudadanos indeseables representados por vagos, borrachos, drogadictos, sodomitas y putas. Al contrario de cómo se proyectó en aquel momento, el crecimiento de la mancha urbana fue exponencial en los últimos 
100 años, pero durante este proceso el centro de la ciudad fue abandonado por la ciudadanía disciplinada occidentalizada y heteronormativa.

Concediendo la oportunidad para ese grupo de personas anti-ciudadanos tomaron cada espacio residual que los grupos sociales más privilegiados habían desechado. De esta manera surgió la mancha de marginalidad urbana (Rojas, 2018, p. 49) que en el caso particular de la capital de San José no fue desplazado al borde o la periferia, sino que lo constituye el centro urbano de la capital.

El centro marginalizado se acentuó y se fortaleció con la presencia de anti-ciudadanos. Gestionando una franja de marginalidad urbana imparable en la capital donde habita todo lo indeseable de la ciudad. Gestionando un imaginario urbano hegemónico que le asignó a este segmento del territorio bajo la idea de que ahí se encuentran las porciones de la ciudad más peligrosas, criminales e insalubres de la capital, entre ellas la zona roja llamada popularmente tierra dominicana.

Con el paso del tiempo las medidas de control políticas y sociales que dominan sobre esa porción del territorio con el fin de desaparecer o sanear la franja de marginalidad urbana se han venido modificando y transformando. Legitimando otras formas de ejercer poder y subordinación, pero al mismo tiempo cambiando los enfoques sobre cuáles son los grupos sociales que se violentan por medio de la privatización de sus derechos ciudadanos que como sujeto civil que tienen. En algunas ocasiones las políticas se acentúan contra grupos étnicos, en otras contra grupos de personas indigentes, en otras contra grupos de personas desplazadas de sus países y territorios de nacimiento.

Llamaremos Cuba Dave Republick (Rivers-moore, 2017) a la forma de anti-Estado donde las personas que ocupan el poder lo hacen a través de formas de subordinación, explotación y violencia. Este anti-Estado está constituido por un conjunto de enclaves y distritos conectados por redes de desplazamiento de bienes y servicios que permiten accionar y funcionar la infraestructura digital y de movilidad precarizada $y$ occidentalizada. No producen su propia infraestructura si no que reciclan y reutilizan la existente en el país con el fin de gestionar la organización social de las personas que producen y consumen del anti-Estado 
Muchos de estos enclaves de la Cuba Dave Republick se encuentran en los valorados sitios turísticos hegemónicos de Costa Rica, como playa Manuel Antonio que es uno de los encaves de un distrito que pertenece a la especialización del comercio sexual producido por hombres homosexuales (scorts) que vienen en su mayoría de Nicaragua ${ }^{3}$, Venezuela y Colombia pasando primero por varios países de la región.

San José, por muchas décadas hasta la actualidad, es el mayor distrito de la Cuba Dave Republick, cuenta con la infraestructura digital, de movilidad y una supra estructura arquitectónica más robusta para esta actividad, desde ahí se ha centralizado la gestión de la mayoría de los bienes y servicios que ofrece el comercio sexual nacional.

Se podría llamar a San José la capital de Cuba Dave Republick, este espacio territorial se ve configurado por el resultado de tres intersecciones de fuerzas económicas producidas por los enclaves de servicios sexuales más predominantes: el comercio sexual heterosexual, que ofrece servicios de dos tipos según el bien que lo produce: las mujeres cisgénero (Rivers-moore, 2019) y las mujeres trans. El tercer enclave sería el comercio sexual entre hombres producido en su mayoría por hombres que mantienen prácticas sexuales con otros hombres por dinero (scorts). Los tres enclaves cuentan con particularidades distintas en su práctica y reproducción, pero con efectos en la desigualdad y violencia estructural muy similares para las personas que sobreviven de ese trabajo.

En los últimos 40 años Cuba Dave Republick ha sido la única porción del territorio donde las personas homosexuales y lesbianas pueden acceder sin fingir ser o comportarse como aburridos fachos heterosexuales normativos. Por lo que se volvió un espacio significativo en términos de vínculos afectivos para estas poblaciones (Rojas, 2018, p. 58). Lo cual generó, más recientemente, las condiciones para la visibilidad de los colectivos trans.

En Cuba Dave Republick se perpetúa la insanidad de la anti-ciudadanía indisciplinada descolonizada y anti-heteronormativa. Los cuerpos disidentes que habitaron Cuba Dave

\footnotetext{
${ }^{3}$ Un scort de Nicaragua se encuentra en condición de desigualdad con respecto a un scort de Colombia y Venezuela, en cuanto a precio y espacio donde ofrecen el servicio, para estos últimos se encuentran en mejores condiciones y cobran tarifas más altas.
} 
Republick los asocian con la criminalidad y lo insalubre, de esta manera evitan contacto con la ciudadanía disciplinada occidentalizada y heteronormativa. Este espacio territorial ha dado origen hoy a un poderoso imperio de relaciones y de prácticas informales que sostienen muchas de las economías hegemónicas dentro de la capital Josefina y el país.

En este contexto se encuentran las condiciones ideales para un devenir trans-urbano. Haciendo referencia al proceso de transformación que ciertas porciones heteronormativas del territorio sufren cuando son desplazadas por dinámicas y economías anti-heteronormativas y anti-capitalistas. En el caso de estudio propuesto para este texto, ese proceso está gestionado por prácticas de socialización de colectivos de personas trans altamente visibles que trabajan en comercio sexual.

En está cartografía usted va poder acercarse a conocer como fue la configuración del espacio público a partir del ejercicio del trabajo sexual un grupo de mujeres transgénero en la década de los 80 's. Con el fin de comprender el fenómeno espacial del comercio sexual realizado por mujeres transgénero. Esta cartografía tiene un enfoque transformador que visibilice, reivindique y contribuya al proceso de emancipación de este colectivo de mujeres.

\section{Trans-Urbanismo}

La configuración del espacio Trans-territorial en Cuba Dave Republick está orientado bajo dos grandes lógicas o puntos corporales cardinales asociadas al estándar de belleza hegemónica heterosexual, que orden la lógica espacial territorial. Al mismo tiempo cada enclave se divide en zonas que son divisiones políticas y espaciales que definen los límites administrativos que cada "Dueña" puede ejercer. Son el resultado de la transformación de un proceso trans-territorial.

Al norte de la ciudad encontramos las chicas más bellas y que ganan más dinero para invertir en silicón y en el rostro. Uno de los enclaves más populares en el espacio público para el trabajo sexual de esta zona es el parque Morazán. Y al sur de la ciudad se encuentran las chicas más feas y que ganan menos dinero para poder invertir en pechos y rostro. Uno de los enclaves más popular en el espacio público para el trabajo sexual 
de esta zona son las aceras alrededor del Ministerio de Obras Públicas y Transportes (MOPT).

Durante la década de los 80 en Costa Rica surge la crisis sanitaria generada por la aparición del virus del VIH-sida por lo que el Estado incrementa las políticas sanitarias y de seguridad contra el grupo identificado como foco de la pandemia: Sodomitas y prostitutas (Jiménez, 2017). Lo que incrementó exponencialmente la aplicación de distintos mecanismos de control y regulación para esta población geopolíticamente localizada en centro urbano de San José, Cuba Dave Republick.

Las travestis o playazas (Kassandra, Comunicación personal, 23 de agosto 2019), ambas son formas auto-identitarias de apropiarse y autonombrarse por el cual se les conocía a las mujeres tras en los años 80's, eran parte de esta población perseguida y acosada por la policía en este contexto hostil. La dinámica cotidiana a la que eran sometidas estas mujeres por parte del cuerpo policial, incluía tratos agresivos o violentos y encarcelamientos frecuentes. Ya que una misma chica podía ser detenida hasta 5 veces en una misma semana (Kassandra, Comunicación personal, 23 de agosto 2019).

El procedimiento consistía en ser llevadas en el vehículo policial o patrulla, que popularmente se le llama: ser montada en la perrera. Y luego ser llevadas a la Unidad de Prevención del Delito (UPD) del departamento de Investigaciones Criminales (DIC) del Organismo de Investigación Judicial (O.I.J) que se ubicaba detrás del actual Tribunal Supremo de Elecciones donde hoy solo existen unas bodegas abandonadas. En ese lugar tenían que pasar la noche para esperar ser llevadas en la mañana siguiente ante un tribunal en la corte suprema de justicia durante las primeras horas de la mañana (Kassandra, Comunicación personal, 23 de agosto 2019).

Se les imponía una fianza de 180 colones $^{4}$ que si no podían pagar serían trasladadas a la antigua penitenciaría el actual Museo de los Niños en los años 70's y luego en la década de los 80's al Centro Penitenciario La Reforma (Kassandra, Comunicación personal, 23 de agosto 2019), donde serían encerradas en una sección especial que le

\footnotetext{
${ }^{4}$ En la década de los 70's y 80's en Costa Rica se continuaba cobrando una multa por 180 colones a las personas por estar de "vago". El monto correspondía a 9 colones diarios por los 20 días laborables del mes.
} 
denominaban El gallinero, un espacio dentro de La Reforma para todas aquellas personas que su crimen no contaba como categoría grave.

A partir de esa década es que se registran de forma oral los primeros testimonios de abusos hacia las mujeres trasgénero que se dedicaban al comercio sexual y aún siguen vivas. Este grupo de mujeres han sido brutalmente perseguidas y reprimidas socialmente hasta la actualidad por el trabajo que ejercen. La policía las declaró enemigas públicas y fue el aparato institucional que más ejerció políticas corporales violentas sobre este grupo de mujeres consideradas una amenaza urbana.

Este apartado pretende compartir algunas de las características inherentes de las tipologías arquitectónicas durante los 80's de San José la capital de Cuba Dave Republick. Él uso y el valor político que estos espacios arquitectónicos tienen para las mujeres transgénero que trabajan en comercio sexual se modifican, cambian o resignifican con el paso del tiempo.

La mayoría de los enclaves son espacios que se trans-forman para solventar necesidades de un grupo de la sociedad que no se considera ciudadanos ni personas. Por lo que gestiona y activa otras formas de organización anti-ciudadana desde un lugar de disidencia. Constituyendo una red de espacios arquitectónicos formales e informales, que brindan servicios complementarios entre ellos y que sostienen a la actividad del comercio sexual considerada ilegítima para una hegemonía.

Los Servicios complementarios los podemos definir como aquellas actividades comerciales que ofrecen servicios que dan soporte o sostienen el comercio sexual y activan economías formales e informales bajo una lógica de micro escala y que son invisibilizadas. Como por ejemplo suministrar servicios de belleza para las chicas que producen más, se puedan mantener y ver bonitas bajo un estándar de belleza heterosexual (Munhurtsberger, Comunicación personal, 06 de abril 2017). O gestionar y regular el consumo de drogas informales tanto para los clientes como para ellas mismas (Kassandra, Comunicación personal, 05 de setiembre 2019).

Muchos de estos espacios se gestionan a partir de consensos entre pequeños y diversos grupos de la sociedad civil con la misma condición precaria y de desigualdad social. Probablemente compartir la misma violencia por distintas formas de discriminación, 
razón por la que se construyen y adquieren su condición de otredad. Incide en la manera que se perciben entre estos grupos, produciendo un mayor grado de empatía entre las personas marginalizadas. En este caso personas asiáticas migrantes en condición irregular y mujeres transgénero que trabajan en comercio sexual.

Estos pequeños consensos, son micro actos políticos (Solá y Urko, 2018) que contribuyen a la acumulación de una economía cuir. En los años 80's la población de migrantes orientales pacto una relación con las chicas transgénero que ejercían prostitución, durante un periodo de represión policial, donde los comercios de restaurantes y pulperías conocidas como "chinos" desempeñaron un papel importante para acceso a servicios de protección y alimentación a varias de las chicas transgénero que se dedicaron al comercio sexual durante esa década. Los propietarios migrantes, muchos en condición irregular, les permitían a las chicas transgénero consumir los servicios de los locales comerciales que estos administraban, en un tiempo que eran expulsadas de manera violenta de todos los espacios de comercio donde la administración eran personas nacionales (Alondra, Comunicación personal, 06 de abril 2017).

La mayoría de las dinámicas de socialización, producción y consumo del espacio se gestionaban por anti-ciudadanos por lo que se consideraban prácticas que atentaban contra el régimen capital y heteronormativo de la época. No tenían como fin generar capital económico o plusvalía inmobiliaria, pero sí generan capital simbólico para las personas que habitaban esos espacios.

Llamaremos capital cuir al conjunto de prácticas de socialización, formas de producción y de consumo que atientan contra los regímenes fundadores (Torres, 2011) del Estado Soberano heterocapitalista occidentalizado (el patriarcado y el capitalismo) y permite la producción de plusvalía que generan valor capital para los cuerpos cuir, en este caso mujeres transgénero que trabajaban en comercio sexual. Acercarnos a la lógica de consumo, producción e invención de estos espacios arquitectónicos nos permite entender las distintas vías de configurar los enclaves de turismo sexual y por qué razón son oprimidos y precarizados en la actualidad.

De esta forma, en los años 80's existía una tipología arquitectónica denominada zonas de tregua (Alondra, Comunicación personal, 06 de abril 2017), que son espacios 
públicos consensuados entre la policía y las chicas transgénero que ejercieron prostitución en una década de mucha represión policial hacia las prostitutas, donde se les permite a las chicas transgénero permanecer sin que la policía aplicara mecanismos de control, vigilancia y violencia sobre sus cuerpos.

Antes de la década de los 90's, la gestión espacial de la mayoría de estas tipologías arquitectónicas no seguían una lógica de producción y consumo espacial de corte liberal como la que domina actualmente. La gestión o producción de espacios bajo esta lógica tiene como fin la privatización del bien común y la explotación precaria de las personas que lo producían. Al contrario, en la década de los 80 's las tipologías arquitectónicas resignificadas por mujeres transgénero que trabajan en comercio sexual generaban capital cuir.

Por ejemplo, la práctica de socialización de dar "vuelta al parque", expresión popular que fue utilizada por mujeres transgénero de los años ochenta que trabajan en comercio sexual para referirse a la acción de derivar por el espacio público en camada, fuera de las zonas de tregua, de manera visible sin miedo a ser violentadas (Kassandra, Comunicación personal, 05 de setiembre 2019). Dar la vuelta el parque significó una práctica de resistencia corporal que manifiesta la urgencia de reconocer y exigir como propio el espacio público (Fournier, 2017, p. 8). Para las mujeres transgénero que trabajan en comercio sexual. Esta práctica contribuyó al proceso de emancipación de este grupo de mujeres y se considera un aspecto significativo para la visibilidad y apropiación del territorio de estos cuerpos marginalizados por la hegemonía.

La economía cuir no se rige bajo parámetros liberales del capital económico y permite gestionar espacios desde una lógica espacial más horizontal. Un ejemplo de este modelo de economía surgió con fuerza en los años ochenta cuando en Costa Rica una buena parte del sector comercial negaba discriminatoriamente los servicios de alojamiento privado en hoteles, cabinas y moteles a personas del mismo sexo, durante la crisis de sanidad producida por el VIH (Fabiola, Comunicación personal, 20 de abril 2017), que sufrieron casi todos los Estados soberanos hetero capitalistas occidentalizados.

Este contexto permitió la creación de una red de espacios de colaboración urbano- rural conocidos como lupanares (Rojas, 2018). El lupanar es una tipología arquitectónica, 
espacios que utilizaron su infraestructura física con el fin de gestionar una diversidad de prácticas afectivas. Existen dos tipologías de lupanares según su modelo de acumulación capital. Los que se rigen bajo un modelo de acumulación de capital, que es afectivo, donde se pone los bienes al servicio de las personas que ocupen el espacio. Tiene un modelo más horizontal. Bajo la gestión de una persona que ofrece el espacio a cambio de una contribución voluntaria (Lorna, Comunicación personal, 06 de abril 2017). Este tipo de lupanar en la década desempeñó un rol significativo durante los años 80 por que permitió la gestión de espacios seguros de socialización y cuido que eran muy escasos en esos contextos (Alondra, Comunicación personal, 06 de abril 2017). Entre estos ejemplos el más significativo fue el lupanar de Alondra que se ubicó en la casa esquinera en calle 3 entre avenida 9 y 11 donde actualmente se encuentra el local comercial de Amón Solar y el Sótano.

Después de la reforma estructural de mediados de la década de los 80 's es que el país empieza a impulsar una serie de políticas neoliberales que inciden en el comercio sexual. Gestionando una lógica que reproduce la privatización espacial de la mayoría de estas tipologías arquitectónicas, la explotación y la precarización de las personas que la producen.

En la actualidad el lupanar tiene un modelo de acumulación de capital, que explotan a las personas que trabajan en el espacio y monopolizan los bienes y servicios que ofrece el espacio. Bajo la gestión de un proxeneta. En la jerga popular se le llaman pensiones. Esta sería la segunda tipología de lupanar basado en su modelo dominante de acumulación.

Sobre la morfología de las tipologías arquitectónicas las mujeres trans se sentían más seguras cuando modelaban en espacios urbanos y arquitectónicos que les permitieran sombrearse (Natalia, Comunicación personal, 08 de agosto 2018). Que es la acción de ocultarse en el espacio público del régimen autoritario y disciplinario ejercido por el estado, comúnmente representado por la policía. Muchos de los edificios del centro urbano no cuentan con esta característica por lo que no era un factor determinante para ejercer la práctica del comercio sexual, pero si algún espacio lo permitía se volvían esquinas muy cotizadas entre las chicas (Natalia, Comunicación personal, 08 de agosto 2018). 


\section{La Zona Norte}

Durante la mañana del viernes 23 de agosto y la tarde del jueves 5 de setiembre de 2019, Kassandra me invita a recorrer junto a ella las calles y avenidas del enclave norte de la ciudad de Cuba Dave Republick. En este espacio Kassandra con 15 años de edad se inició en el comercio sexual. Trabajó como prostituta, autodenominada por ella misma de esa manera, durante un periodo de casi 5 años de 1978 a 1983 (Kassandra, Comunicación personal, 16 de agosto 2019). La razón por la que decidió abandonar el comercio sexual fue por que contrajo matrimonió de manera simbólica con una persona identificada como hombre cisgénero heterosexual con quien construyó un vinculo romántico en la década de los ochenta.

Su experiencia de vida es un reflejo de las circunstancias contextuales inmediatas, creció en el barrio Cuba, uno de los asentamientos más empobrecidos del sur de la capital. Kassandra se autodefine en la infancia como un niño muy afeminado (cuerpo feminizado). En ese lugar pudo probar las drogas y prácticas sexuales con otros hombres desde muy temprana edad, a los 11 años ya consumía marihuana y mantenía prácticas sexuales con hombres mayores a ella, y en algunas ocasiones generando beneficio de estas relaciones, ya que era consciente de que era menor de edad.

Kassandra declara pública su identidad sexual disidente muy joven, lo cual le trajo conflictos con sus familiares directos, generando dinámicas muy tóxicas y violentas en la convivencia cotidiana en casa. Por esa razón a los 14 decide huir de su casa sin ningún tipo de recurso económico o material. Con la incertidumbre de no tener claro hacia donde ir Kassandra decide pide ayuda. La Gata es una mujer trans que administra una cuartería o lupanar donde explotan a varias chicas trans en comercio sexual. Que se ubicaba en la cercanía donde vivía Kassandra, por lo que decide acudir a ella por ayuda. En palabras de Kassandra:

y yo llegué a la casa como a las cuatro y media cinco de la tarde, di vueltas con el maletincillo, un montón, porque no sabía para dónde irme. Pero yo sí sabía que iba a ir a vestirme mujer.

Yo toqué esa puerta en mi abrió un señor, porque allí en ese momento todos eran señores, solo en la noche eran señoritas. Me abrió un señor y yo le dije: 
¿Aquí vive Leonela? entonces el muchacho, que después ya yo lo conocí, bueno el señor, era un señor. Maquiva dice: isi La Gata!

Entonces La Gata se asomó por una ventanita así, y donde me vio me dice: ¿hola cómo está? Yo le dije: Bien. Y me dice: ¿que anda haciendo? y seguro alguien dentro de la casa le preguntó: ¿quién es? pase... y me abrió la puerta. Yo entré, había un montón de cuartos, pero cuartitos así con "playbook". En el primer cuarto vi una de ojos gatos maquillándose.

La Gata me pasó al cuarto y ya yo me senté, y ella estaba fumando un puro y me lo paso yo le di. Y me dijo que anda haciendo, entonces ya yo me puse a llorar y le conté. Y La Gata me dijo no se preocupe ahora yo la mudo. Ella me maquilló, me alistó y me fui para la bíblica de una, duré una semana sin componer un colón. (Kassandra, Comunicación personal, 16 de agosto 2019)

De esta manera Kassandra tiene su primer ritual de iniciación en el comercio sexual y en el travestismo. Viviendo con la Gata, Kassandra consiguió un espacio de protección, alimento y techo pero sobre todo consiguió un espacio bajo una lógica afectiva para poder expresar su identidad sexual disidente de manera segura. Estos espacios son significativos, en términos del vínculo afectivo, para estas mujeres porque en ellos sucede la transmisión del conocimiento de la figura de mayor jerarquía la madre en este caso la Gata a todas sus hijas.

Para este apartado se trató de construir una lista de tipologías arquitectónicas basada en las categorías que se explican anteriormente en el cuerpo del texto. Estos espacios se identificaron utilizando de referencia la experiencia de vida de Kassandra durante sus años de explotación en el comercio sexual, mientras realizábamos juntxs el recorrido urbano. A continuación, un listado de las tipologías arquitectónicas más representativas de la zona norte y sur de aquella época en que Kassandra ejercía comercio sexual:

\section{Zona Norte}

La figura de la Dueña es aquella persona legítima encargada de administrar y gestionar las prácticas de consumo y producción relacionadas a los servicios complementarios que ofrece el comercio sexual en la zona que administra 


\section{La Doña:}

La zona era territorio de La Tania (la torro mágico) quien era la dueña de la zona por venta de piedra.

\section{Servicios complementarios}

\section{Bar y restaurantes:}

- Restaurante chino

- Bar de Danny un cubano

- Bar Gersi

- Bar y pensión de Rivas de Juana gallo

- Bar la Copa

- Bar trafico unos de los más famosos

- Bar la llave de plata

- Bar la moderna

- Bar Amelia

- Bar Lunader

\section{Comercio:}

- La Pulpería de Briceño

- Zulma la diseñadora de los trajes.

- Soda los Topoyiyos

- Teatro Adela

Lupanares populares P1: el alquiler en ese momento oscilaba entre los 300 y los 900 colones mensuales.

- Pensión cañas propietaria Ana Gómez. Conocida como la pata de oso vivió mucho tiempo del culo de los playos. 
- Las panameñas que se conforman por 4 mujeres migrantes conocidas como Estrella, Gloria Mayo, Jennifer y la Cristaloves

- Pensión de Estela

- Pensión de Joel (Shairon)

- Espolett

- Pensión de mico de Hule

- Hotel el comerciante (el primer hotel gay abiertamente en la capital)

- Hotel el comerciante anexo

- Pensión de Alaska y Paula (hoteles de putas) las más finas y jóvenes, eran rivales.

- Pensión de doña paz

- Hotel Maravilla (La antesala del infierno) practicaban abortos clandestinos, proxenetismo y venta de drogas

- Lorna alquiló la casa, y es donde se encuentra el actual bar el Sótano en barrio Amón por 15 rojos al mes (con cochera) y lo convirtió en lupanar.

\section{Lupanares populares P2:}

- La casa de Jessenia (a la par del bar la copa)

- La libanesa de Negras

\section{Clínicas clandestinas:}

- Joaquín Lujol, El doctor administraba una clínica clandestina para ponerle tetas a las mujeres trans, donde utilizaba aceite marca Lujol para realizar implantes mamarios, este tipo de aceite se usaba en caballos con fines veterinarios. Por este procedimiento altamente riesgoso para la salud de las chicas cobraba entre 50 a 100 colones, dependiendo del brete y el tamaño de las tetas. Le llamaban la clínica de las muñecas. 


\section{Zona Sur}

\section{La Doña:}

La Rebeca Chancho, personaje trans y prostituta de los 80's. Administraba la zona del MOPT.

\section{Servicios complementarios}

\section{Bar y restaurantes:}

- Night club Pantera Rosa (donde Lorna aprendió a maquillar y peinar)

\section{Comercio:}

- Hospital privado clínica bíblica

\section{Lupanares populares P1:}

- La casa de las orquídeas la administraba Lorna, vivió con La Gata (Juliana) en 1978

\section{Lupanares populares P2:}

- La casa de Harry Spanish, donde trabajo la Toña la primera chica trans con discapacidad cognitiva de la que se tiene registro, que trabajaba como empleada doméstica en este lupanar (se encontraba dónde está el actual parqueo a la par del bar La Avispa) 


\section{Conclusiones}

Para abordar aspectos relacionados a las conclusiones propongo dos nociones que he llamado lo etimológico y lo espacial. Sobre lo etimológico las conclusiones van dirigidas en dos direcciones.

La primera dirección es hacia una crítica cuir estructural sobre la práctica pedagógica en la academia. Durante este ejercicio, me reforzó la idea de que el espacio académico debe replantearse las prácticas y hábitos de aprendizaje que utiliza para validar y jerarquizar las distintas formas de conocimiento que considera como legítimas. La academia como espacio de transformación social debe posibilitar y reconfigurar su orden hegemónico hacia un devenir trans-académico que le permita transitar hacia otras formas más sanas y horizontales de producir y transmitir el conocimiento de manera situada y militante. $Y$ también permita ser una plataforma de visibilidad del conocimiento producido por otros grupos construidos socialmente como otredad en las últimas décadas (Vengas y Moreno, 2020, p. 83).

Y la otra dirección, sería una perspectiva cuir militante sobre las nociones que construyen las políticas de las reformas liberales que se han venido implementando en la región latinoamericana a partir de la década de los años 80's han debilitado la estructura política y económica de los territorios que los componen a gran escala. Si no que también a pequeña escala a debilitado el tejido social de los grupos más marginalizados entre ellos los colectivos de mujeres transgénero que trabajan en comercio sexual en las zonas urbanas, como es el caso de Cuba Dave Republick. Obstaculizando la organización ciudadana de estas mujeres de forma activa que posibilite consensos en condiciones más horizontales, donde sean escuchadas y respetadas con el fin de dar acceso a diferentes bienes, servicios públicos y derechos inherentes que el Estado soberano hetero-capitalista occidentalizado les han negado históricamente.

Este texto es un esfuerzo por contribuir a la memoria de un colectivo de mujeres transgénero que pierden fuerza política y contestataria con forme intentan formalizar o regularizar sus esfuerzos y colectivos para obtener "ayuda" internacional de aparatos financieros hetero-capitalistas. Estos organismos intentan insertar a estas mujeres en una lógica dominante neo-liberal ajenas a su propia lógica. En este proceso se 
transfieren y re-significan valores sociales que cambian drásticamente la manera de interactuar de las personas que se integran a este modelo liberal más individual. El reto de estas nuevas formas de organización social en torno a la lucha de los colectivos transgénero es no transformar sus valores sociales colectivos asociados al bien común durante este proceso. Al contrario, estos valores deberían fortalecerse durante el proceso con el fin de que no olviden de donde vienen para que mantengan en claro hacia dónde van.

Y sobre lo espacial es importante recalcar que estos espacios trans-territoriales juegan un papel importante para entender o aproximarnos a la experiencia urbana desde una mirada de una mujer trans en ese contexto específico. Pero, además, reconocer la urgencia de un proyecto de memoria urbana histórica para estos colectivos. Considero que el mayor aporte del texto es la creación de una posible herramienta y ejercicio metodológico de mapeo urbano para el empoderamiento ciudadano desde una memoria que se está construyendo de manera paulatina, que ayude a fortalecer el tejido social de la comunidad trans que se está formando en el país actualmente.

\section{Referencias}

Benach, J, Montse, V., Carles, M. (2008). Desigualdad en salud: Ia mayor epidemia del siglo XXI. Papeles de relaciones ecosociales y cambio global.

Cervetto, R., López, M. (2017). Agítese antes de usar: desplazamientos educativos, sociales y artísticos en América latina. Teorética.

Falconí, D., Castellanos S., Viteri M. A. (ed.) (2014). Resentir lo queer en América Latina: diálogos desde / con el sur. Editorial Egales.

Falconí, D. (ed.) (2018). Inflexión marica, escrituras del descalabro gay en América Latina. Editorial Egales.

Gallo, B. (11 de mayo 2019). ¿Cuánto cuesta un coyote para atravesar la frontera? Aseguran que es más barato en familia. El Diario https://eldiariony.com/2019/05/11/cuanto-cuesta-un-coyote-para-atravesar-lafrontera-aseguran-que-es-mas-barato-en-familia/

Jiménez, J. D. (2017). Entre la ciencia y la cultura: La conformación de discursos médicos sobre la homosexualidad en el contexto del surgimiento del VIH/Sida en Costa Rica. Anuario de Estudios Centroamericanos UCR, 43, 419-445.

Preciado, B. (2014, 8 de marzo). El burdel del Estado. [video] Youtube https://www.youtube.com/watch?v=dO8L5Y9WJpo

Preciado, P. B. (2020). Texto yonqui: sexo, drogas y biopolítica. Anagrama.

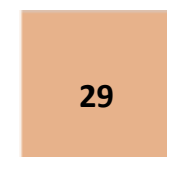

Cuadernos del CILHA n $34-2021$ 
Trans-Urbanismo: economía cuir afectiva en el trabajo sexual por mujeres trans en los años 80’s en San José Costa Rica

Quesada, F. (2011). La modernización ente cafetales San José, Costa Rica, 1880-1930. Editorial UCR.

Registro general de concesiones en polo turístico Golfo de Papagayo. (1993, 2 de septiembre). Decreto ejecutivo 2248-MP-J-TUR. La Gaceta, 174.

Rivers-Moore, M. (2017) Son machistas las tratan mal: masculinidad transnacional comparativa en el turismo sexual. Editorial UCR.

Rivers-Moore, M. (2019). Gringo Gulch, sexo, turismo y movilidad social en Costa Rica. Editorial UCR.

Rojas Herra, L. (26 de mayo 2020). Territorios: Respuestas sociales y de resistencia desde grupos LGBTIQ en la ciudad frente al COVID-19. Revista Rupturas, 10, 73-82.

https://revistas.uned.ac.cr/index.php/rupturas/article/view/2927

Rojas Herra, L. (julio-diciembre, 2019). Bitacorá de un playo en cuarentena: relatos del orto. Indetidades. Revista de Ciencias Sociales y Humanidades, 9 (15), 120-146.

Rojas Herra, L. (3 de diciembre 2018). "Aprender a correr en tacones": producción de espacio urbano de las minorías diversas en San José, Costa Rica. BlogURBS, Estudios urbanos y ciencias sociales.

http://www2.ual.es/RedURBS/BlogURBS/aprender-a-correr-en-tacones-produccion-de-espacio-urbano-delas-minorias-diversas-en-san-jose-costa-rica/

Sandoval García, C., Fournier Pereira, M. (2017). Género, clase y afectividad: vínculos y comunicación en una comunidad trans [Tesis de maestría, programa de posgrado en comunicación Universidad de Costa Rica] Repositorio institucional UCR http://repositorio.sibdi.ucr.ac.cr:8080/jspui/handle/123456789/8641

Sassen, S. (1999). La ciudad global: New York, Londres, Tokio. EUDEBA.

Sassen, S. (2003). Contrageografías de la globalización género y ciudadanía en los circuitos transfronterizos. Traficantes de sueños.

Sassen, S. (2010). Territorio, autoridad y derechos: de los ensamblajes medievales a los ensamblajes globales. Katz.

Sassen, S. (2015). Expulsiones brutalidad y complejidad en la economía global. Katz.

Solá, M y Urko, E, corp. (2018). Transfeminismos epistemes, fricciones y flujos. Ediciones Txalaparta.

Torres, D. J. (2011). Porno Terrorismo. Txalaparta.

UNODC (Oficina de las Naciones Unidas contra droga y el delito). (2011). Algunos datos relevantes sobre la trata de personas. https://www.unodc.org/documents/lpo-brazil/sobre-

unodc/Fact_Sheet_Dados_Trafico_de_Pessoas_geral_ESP.pdf

Venegas Martínez, J., Moreno Medrano, L. M. S. (jul.-dic. 2020). Breve panorama histórico de la educación intercultural en América Latina. DIDAC, 76, 2020: 77-85. https://doi.org/10.48102/didac.2020..76_JUL-

DIC.30

\section{Entrevistas}

Fabiola (20 de abril 2017). Entrevistada por L. Rojas Herra. Asociación Transvida.

Lorna (6 de abril 2017). Entrevistada por L. Rojas Herra. Asociación Transvida. 
Munhurtsberger, A. (6 de abril 2017). Entrevistada por L. Rojas Herra. Asociación Transvida.

Alondra. (06 de abril 2017). Entrevistada por L. Rojas Herra. Alondra. Realizada el en la Asociación Transvida.

Porras, N. (08 de agosto de 2018). Entrevistada por L. Rojas Herra. Asociación Teorética.

Kassandra (08 de agosto de 2018). Entrevistada por L. Rojas Herra. Asociación Teorética.

\section{Recorrido urbano}

Kassandra (23 de agosto 2019). Recorrido Urbano.

Kassandra (05 de setiembre 2019). Recorrido Urbano. 